Article

\title{
Suzuki-Miyaura C-C Coupling Reactions Catalyzed by Supported Pd Nanoparticles for the Preparation of Fluorinated Biphenyl Derivatives
}

\author{
Roghayeh Sadeghi Erami ${ }^{1,2}$, Diana Díaz-García ${ }^{1}$, Sanjiv Prashar ${ }^{1}$, \\ Antonio Rodríguez-Diéguez ${ }^{3}$, Mariano Fajardo ${ }^{1}$, Mehdi Amirnasr ${ }^{2}$ and \\ Santiago Gómez-Ruiz ${ }^{1 \text {,* }}$ \\ 1 Departamento de Biología y Geología, Física y Química Inorgánica, ESCET, Universidad Rey Juan Carlos, \\ Calle Tulipán s/n, E-28933 Móstoles (Madrid), Spain; romochem@gmail.com (R.S.E.); \\ dianadiazgarcia2@gmail.com (D.D.-G.); sanjiv.prashar@urjc.es (S.P.); mariano.fajardo@urjc.es (M.F.) \\ Department of Chemistry, Isfahan University of Technology, Isfahan 84156-83111, Iran; amirnasr@cc.iut.ac.ir \\ Departamento de Química Inorgánica, Universidad de Granada, 18071 Granada, Spain; antonio5@ugr.es \\ * Correspondence: santiago.gomez@urjc.es; Tel.: +34-914-888-507
}

Academic Editor: Ioannis D. Kostas

Received: 20 December 2016; Accepted: 24 February 2017; Published: 28 February 2017

\begin{abstract}
Heterogeneous recyclable catalysts in Suzuki-Miyaura C-C coupling reactions are of great interest in green chemistry as reusable alternatives to homogeneous $\mathrm{Pd}$ complexes. Considering the interesting properties of fluorinated compounds for the pharmaceutical industry, as precursors of novel materials, and also as components of liquid crystalline media, this present study describes the preparation of different fluorinated biphenyl derivatives by Suzuki-Miyaura coupling reactions catalyzed by a heterogeneous system (G-COOH-Pd-10) based on $\mathrm{Pd}$ nanoparticles supported onto $\mathrm{COOH}$-modified graphene. The catalytic activity of the hybrid material G-COOH-Pd-10 has been tested in Suzuki-Miyaura C-C coupling reactions observing excellent versatility and good conversion rates in the reactions of phenylboronic acid, 4-vinylphenylboronic acid, 4-carboxyphenylboronic acid, and 4-fluorophenylboronic acid with 1-bromo-4-fluorobenzene. In addition, the influence of the arylbromide has been studied by carrying out reactions of 4-fluorophenylboronic acid with 1-bromo-2-fluorobenzene, 1-bromo-3-fluorobenzene, 1-bromo-4-fluorobenzene, 2-bromo-5-fluorotoluene, and 2-bromo-4-fluorotoluene. Finally, catalyst recyclability tests show a good degree of reusability of the system based on G-COOH-Pd-10 as the decrease in catalytic activity after five consecutive catalytic cycles in the reaction of 1-bromo-4-fluorobenzene with 4-florophenylboronic acid at 48 hours of reaction is lower than $8 \%$ while in the case of reactions at three hours the recyclability of the systems is much lower.
\end{abstract}

Keywords: Pd nanoparticles; C-C coupling; fluorinated compounds; graphene; supported catalysts; Suzuki-Miyaura reactions

\section{Introduction}

Palladium-catalyzed reactions have been one of the main methods for C-C cross-coupling processes [1]. In particular, Suzuki-Miyaura are one of the most widely used reactions for the preparation of biphenyl derivatives [2]. These reactions have been principally carried out using homogeneous catalysts based on simple or sophisticated Pd complexes [2-5]. However, the current needs of industry and the search for greener alternatives to these catalyst are pushing the development of new heterogeneous and recyclable systems [6]. These heterogeneous C-C coupling catalysts are based on either supported palladium complexes $[7,8]$ or supported palladium nanoparticles [9]. 
Most of the studied palladium-based heterogeneous catalytic systems have shown lower efficiencies and catalytic activities than homogeneous counterparts [9]. Nevertheless, current research advances of the scientific community have led to the development of highly active, reusable, and robust heterogeneous systems. The majority of these systems are based on palladium nanoparticles (PdNPs) which take advantage of their interesting properties, such as high surface area and high catalytic activity [9].

In addition, supporting PdNPs on different nanostructured materials enhances the recyclability properties and facilitates the separation of the products which are usually dissolved in the reaction mixture [10]. Thus, the ongoing research in this topic is very intensive because there is still much work that needs to be done to improve the catalytic performance of the supported systems. Therefore, many groups are working on supporting Pd nanoparticles onto mesoporous silica [11,12], alumina [13,14], graphene [15,16], modified graphene [17,18], graphene oxide [19], graphite oxide [20], reduced graphene oxide [21], or other carbon-based materials [22], for example, for the development of novel catalytic systems. However, with supported catalysts considerable work still needs to be carried out in order to increase the versatility of the reagents and products of the C-C coupling reactions.

In this context, our group has decided to study the preparation of different fluorinated biphenyl derivatives by Suzuki-Miyaura coupling reactions. In general, fluorinated compounds, although generally viewed as mostly inert because of their lack of chemical reactivity [23], may have biological activity which could be of interest in different therapies. For example simple and accepted compounds, such as Prozac ${ }^{\mathrm{TM}}$, Redux ${ }^{\mathrm{TM}}$, or 5-fluorouracyl, are fluorinated compounds with anti-depressant, anti-obesity, and anticancer properties, respectively. Furthermore, there is a long list of fluorine-containing drugs that have been introduced to the market during last two decades [24]. The incorporation of fluorine in drugs normally improves their metabolic stability and impedes the oxidative attack of cytochrome P450 enzymes, thus improving their activity in vivo [25]. Pharmaceutical use is not the unique application of F-containing organic derivatives, for example, fluorination compounds are used to improve material properties opening new fields of research [26]. In particular, fluorinated biaryl derivatives are highly suitable as components of liquid crystalline media [27] and, in the form of ethers, have also recently been considered as pro-drug scaffolds employing the chemical-microbial approach [28].

We have only found in the literature a few examples reporting the preparation of fluorinated biaryl derivatives via $\mathrm{C}-\mathrm{C}$ coupling catalytic reactions. Almost all of these reports described homogeneous systems based on Pd-complexes as catalysts [29-35], while only one study was carried out using Pd nanoparticles [36]. Therefore, we report here the synthesis and characterization of palladium nanoparticles supported onto commercial graphene modified with $\mathrm{COOH}$ groups and the study of the application of this composite material in Suzuki-Miyaura C-C coupling heterogeneous catalytic reactions in the formation of fluorinated biphenyls. We have studied different parameters for this reaction, including the recyclability of the catalytic systems. Furthermore, we have developed a new quantification method, as an alternative to gas chromatography (GC) or high-performance liquid chromatography (HPLC) for the fluorinated products of the catalytic reactions based on a simple ${ }^{19}$ F-NMR study using an internal standard method.

\section{Results and Discussion}

\subsection{Synthesis and Characterization of the Supported PdNPs}

Supported palladium nanoparticles were prepared by the reaction of commercial $\mathrm{COOH}$-modified graphene (G-COOH) with different amounts of $\left[\mathrm{PdCl}_{2}(\mathrm{cod})\right]$ in toluene for 48 hours. The supported PdNPs were presumably formed via the reduction of $\left[\mathrm{PdCl}_{2}(\mathrm{cod})\right]$ as was previously reported by our group for silica- and titania-based materials $[12,14,37,38]$. This synthetic method requires the reduction of the organometallic palladium complex which is achieved by toluene and the carbon atoms at the surface of the graphene which presumably act as the reducing agents. In addition, an agglomeration 
of the graphene layers occurs giving rise to the formation of a hybrid material that consists mainly of a graphite support in a mixture of phases and impregnated palladium nanoparticles.

This reaction was repeated using different amounts of the organometallic $\mathrm{Pd}$ precursor $\left[\mathrm{PdCl}_{2}(\mathrm{cod})\right]$ to study the Pd loading on the materials which was determined by $\mathrm{X}$-ray fluorescence (XRF) analysis. Thus, a theoretical amount of $5 \mathrm{wt} \%, 10 \mathrm{wt} \%$, and $15 \mathrm{wt} \%$. Pd was used for the reactions to give the materials G-COOH-Pd-5, G-COOH-Pd-10, and G-COOH-Pd-15, respectively. After analysis of the materials by $\mathrm{XRF}$, the incorporation of palladium to the material was $3.06 \mathrm{wt} \%$, $7.93 \mathrm{wt} \%$, and $11.20 \mathrm{wt} \%$ Pd. for G-COOH-Pd-5, G-COOH-Pd-10, and G-COOH-Pd-15, respectively. Therefore, the higher Pd efficacy was achieved for G-COOH-Pd-10 (79.3\%) while in the case of G-COOH-Pd-5 and G-COOH-Pd-15 this value was 61.2\% and 74.6\%, respectively (Table 1 and Table S1 of Supplementary Material). The differences in the incorporation rate are not very high. Other materials have shown that the loading capacity follows a logarithmic tendency as the material saturates and limits the reduction of the $\mathrm{Pd}$ (II) complex to palladium nanoparticles [12]. This may be the reason for the lower Pd incorporation rate found for G-COOH-Pd-15. In general, these materials showed higher loading capacities than other silica-based materials reported previously by our group [12], similar Pd incorporation to that found for other C-based materials [15-20] and slightly lower than in the case of alumina submicronic particles [14].

Table 1. Theoretical and experimental $\mathrm{Pd}(\mathrm{wt} \%)$ quantity and $\mathrm{Pd}$ incorporation rate (\%) in materials G-COOH-Pd-5, G-COOH-Pd-10, and G-COOH-Pd-15.

\begin{tabular}{cccc}
\hline Material & $\begin{array}{c}\text { Theoretical Pd Quantity } \\
\text { (wt \%) }\end{array}$ & $\begin{array}{c}\text { Experimental Pd } \\
\text { Quantity (wt \%) }\end{array}$ & $\begin{array}{c}\text { Incorporation } \\
\text { Rate (\%) }\end{array}$ \\
\hline G-COOH-Pd-5 & 5 & 3.06 & 61.2 \\
G-COOH-Pd-10 & 10 & 7.93 & 79.3 \\
G-COOH-Pd-15 & 15 & 11.20 & 74.6 \\
\hline
\end{tabular}

Bearing in mind that the most effective incorporation of $\mathrm{Pd}$ in the material was achieved for G-COOH-Pd-10, this catalytic system was selected for the catalytic studies and for further characterization. G-COOH-Pd-10 was then studied by transmission electronic microscopy (TEM). The TEM image of G-COOH-Pd-10 (Figure 1a) shows that this material contains Pd nanoparticles that can be easily observed as black dots impregnated on the external surface of the carbon-based support materials. The obtained PdNPs have a poorly defined shape with a size of $14.6 \pm 1.4 \mathrm{~nm}$. $\mathrm{Pd}$ nanoparticle size distribution (Figure $1 \mathrm{~b}$ ) has been calculated by using the software ImageJ $(1.51 \mathrm{j}$, Wayne Rasband, National Institutes of Health, MD, USA, 2017) [39] and a subsequent Gaussian fit using Origin (OriginLab 8.0, Northampton, MA, USA, 2009). In addition, the TEM image (Figure 1) shows that the larger palladium particles are formed by clusters of small Pd nanoparticles (for additional images see Figures S1-S3 of the Supplementary Material).

In addition, the material was characterized by Fourier-transformed infrared spectroscopy (FT-IR), $\mathrm{N}_{2}$ adsorption-desorption isotherms (BET), and X-ray diffraction (XRD). The FT-IR spectrum shows the expected signals for the $\mathrm{O}-\mathrm{H}$ vibration, stretching band of the $\mathrm{C}=\mathrm{O}$ and vibration of the $\mathrm{C}-\mathrm{O}$ bond of the $\mathrm{COOH}$ groups at ca. 2900, 1600-1750, and $1100 \mathrm{~cm}^{-1}$, respectively (Figure S4 of the Supplementary Material). The characterization by $\mathrm{N}_{2}$ adsorption-desorption isotherms (BET method), showed a specific surface area of material G-COOH-Pd- 10 of $4.1 \mathrm{~m}^{2} / \mathrm{g}$ and an irregular pore size distribution of the material. The measurements showed type III isotherms (Figure 2) according to the IUPAC classification [40] which is indicative of non-porous materials with low affinity adsorbent-adsorbate. The measured surface areas by BET studies is much lower than the theoretical surface area limit of graphene which is estimated to be ca. $2600 \mathrm{~m}^{2} / \mathrm{g}$. Therefore, material G-COOH-Pd-10 in dry state is probably affected by the stacking of the graphene sheets, causing a decrease in its surface area. This also indicates that the nitrogen gas of the BET analysis does not easily penetrate the graphene layers of the material giving type III isotherms of low surface area. The partial stacking of layers in the 
dry state, while measuring the textural properties of the materials giving low surface area, has been previously observed in similar systems [19].

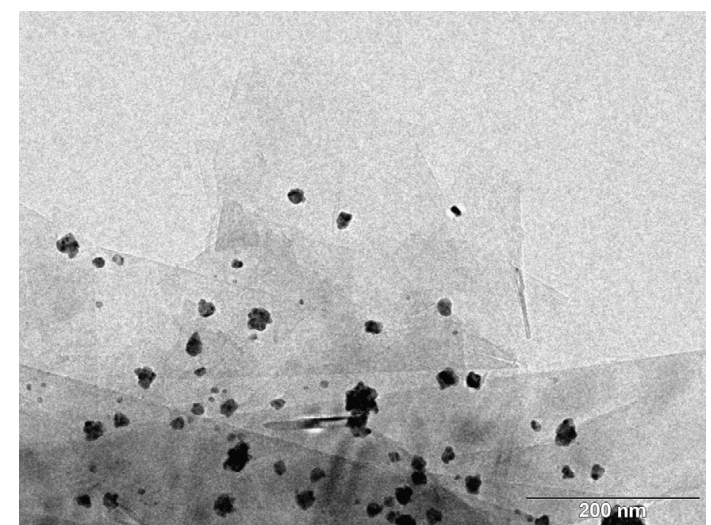

(a)

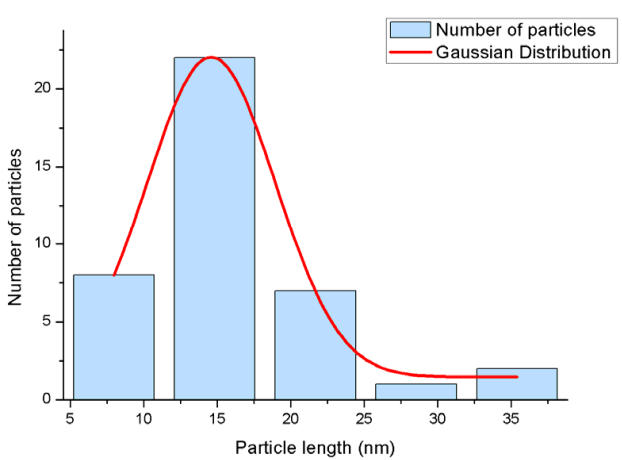

(b)

Figure 1. (a) Transmission electronic microscopy (TEM) image of the material G-COOH-Pd which consists of Pd nanoparticles supported on a graphite support in a mixture of phases; and (b) Pd-particle size Gaussian distribution.

In spite of the partial stacking of the layers detected in the BET analysis, an interesting difference in the adsorptive parameters of the material after Pd-functionalization was observed, namely, a decrease in the surface area, a slight increase in the Barnett, Joyner and Halenda (BJH) adsorption or desorption cumulative volume of pores and a slight decrease in the $\mathrm{BJH}$ adsorption or desorption cumulative surface area of pores (Table S2 and Figure S5 of the Supplementary Material). These changes indicate the impregnation of the Pd nanoparticles on the external surface which decreases the surface area and slightly increases the estimated pore volume. This reveals that the Pd nanoparticles perturb the pure stacking of the graphene layers because the impregnation of the particles in the material increases the distance between layers due to the intercalation of the metal nanoparticles.

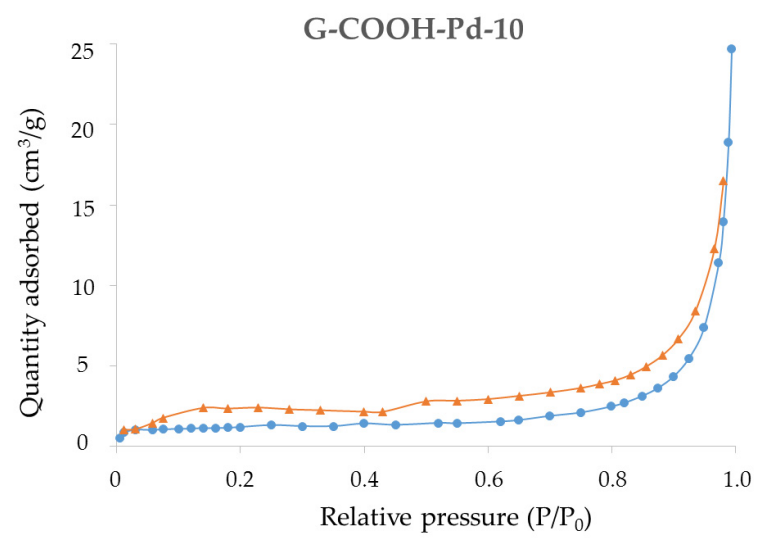

Figure 2. $\mathrm{N}_{2}$ adsorption-desorption isotherm of material G-COOH-Pd-10.

Finally, the material G-COOH-Pd-10 was characterized by powder XRD to confirm the presence of Pd nanoparticles. The XRD pattern (Figure S6 of the Supplementary Material) shows the peaks corresponding to a mixture of carbon-based materials with graphite as a broad peak at a $2 \theta$ of ca. $26^{\circ}$ (indicating the partial agglomeration of graphene layers to graphite) and the peaks assigned to the $\mathrm{Pd}$ nanoparticles at $39^{\circ}, 43^{\circ}, 67^{\circ}, 78^{\circ}$, and $84^{\circ}$ corresponding to the Miller planes (111), (200), (220), (311), and (222), respectively. This confirms, therefore, the presence of Pd nanoparticles impregnated onto the carbon-based material, as was previously observed in TEM images. 


\subsection{Catalytic Study}

\subsubsection{Determination of the Optimal Conditions and Influence of Different Boronic Acids}

The heterogeneous catalyst G-COOH-Pd-10 was tested in four coupling reactions of 1-bromo-4fluorobenzene as aryl bromide with boronic acids with different substituents, namely, phenylboronic acid, 4-vinylphenylboronic acid, 4-carboxyphenylboronic acid and 4-fluorophenylboronic acid and (Scheme 1, reactions a-d, respectively).

The reaction conditions were determined previously by our group using analogous supported catalysts based on palladium nanoparticles and silica or alumina [12,14]. Thus, all of the catalytic tests of this study were carried out using a DMF $/ \mathrm{H}_{2} \mathrm{O}$ (95:5) mixture as solvent, $\mathrm{K}_{2} \mathrm{CO}_{3}$ as the base, and two different temperatures $\left(70^{\circ} \mathrm{C}\right.$ and $\left.110^{\circ} \mathrm{C}\right)$. The reactions were carried out at different time intervals of $3,8,24$, and $48 \mathrm{~h}$, in order to determine the kinetic parameters of each reaction.

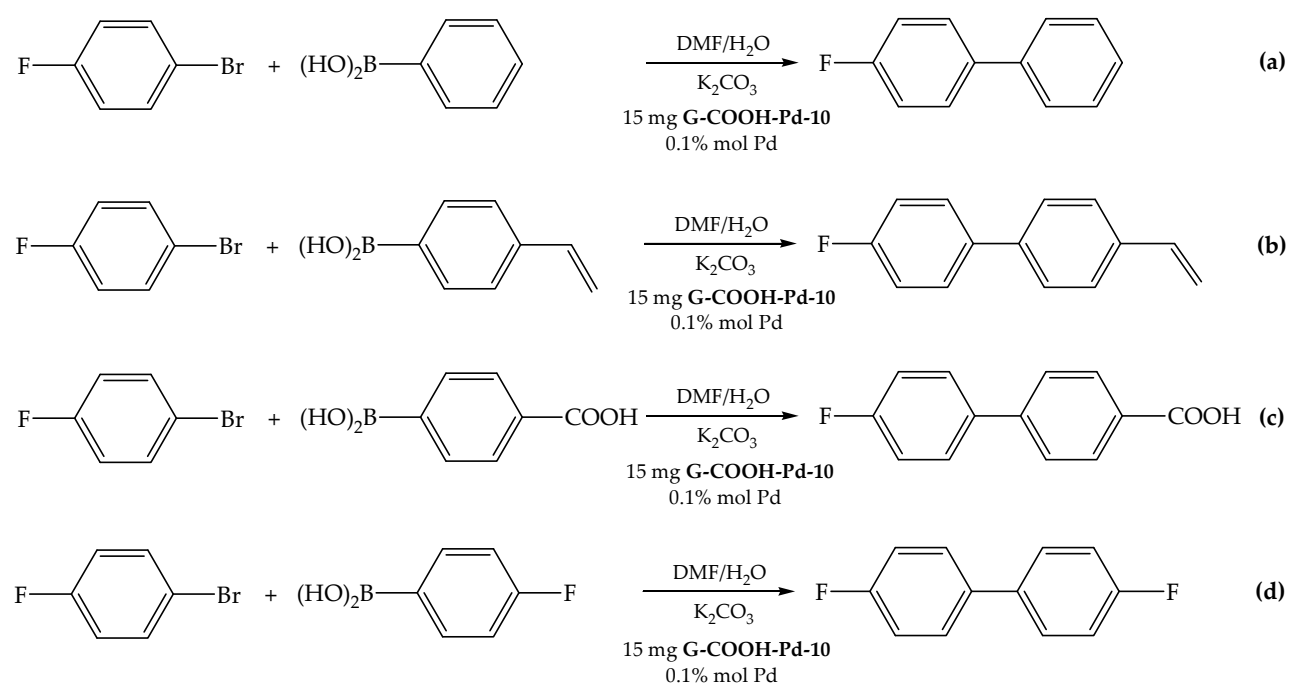

Scheme 1. Reaction of 1-bromo-4-fluorobenzene with (a) phenylboronic acid; (b) 4-vinylphenylboronic acid; (c) 4-carboxyphenylboronic acid; and (d) 4-fluorophenylboronic acid catalyzed by G-COOH-Pd-10.

The results obtained in the C-C cross-coupling reactions of Scheme 1 at different time intervals are given in Table 2 and presented in Figure 3. In general, the increase of the temperature from 70 to $110^{\circ} \mathrm{C}$ results in higher conversion percentages as expected for this kind of reaction.

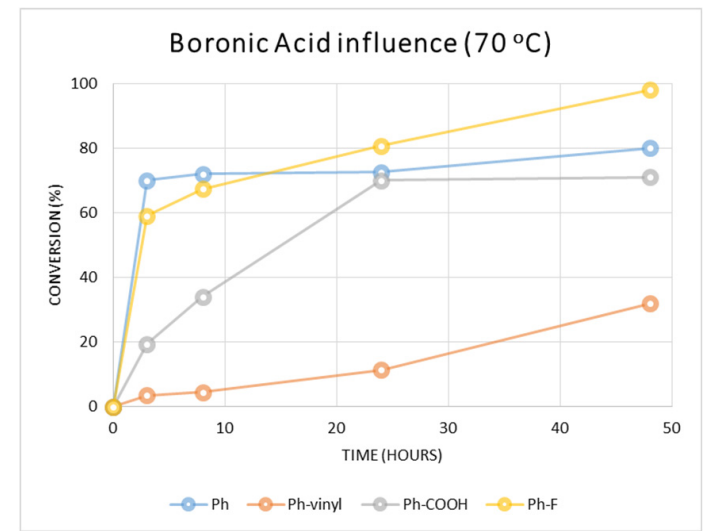

(a)

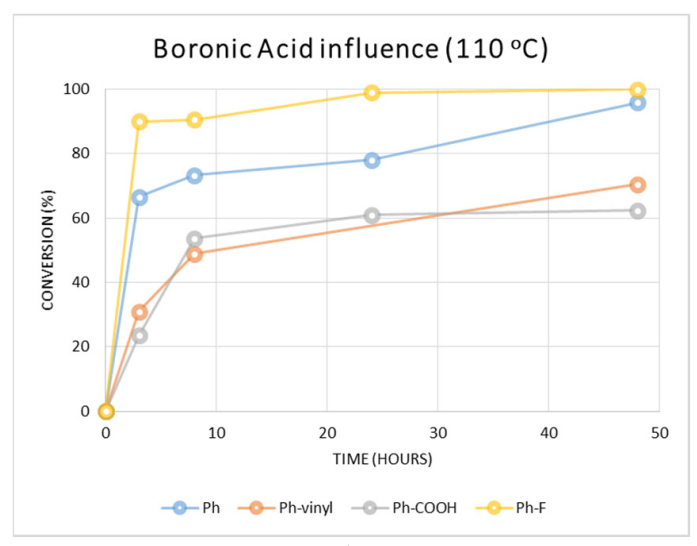

(b)

Figure 3. Conversion vs. time in the reaction of different boronic acids and 1-bromo-4-fluorobenzene catalyzed by G-COOH-Pd-10: (a) at $70{ }^{\circ} \mathrm{C}$; and (b) at $110{ }^{\circ} \mathrm{C}$. 
However, these results are in contrast with the previous study of Pd-supported nanoparticles using mesoporous silica-based materials such as MSU-2 or SBA-15 [12] in which a decrease in the catalytic activity was observed when increasing the temperature, due to a higher mobility of the nanoparticles which increase the aggregation of the catalytic centers, thus, decreasing the catalytic activity.

Table 2. Bromide conversions in C-C coupling reactions using 1-bromo-4-flurobenzene and different boronic acids catalyzed by G-COOH-Pd-10.

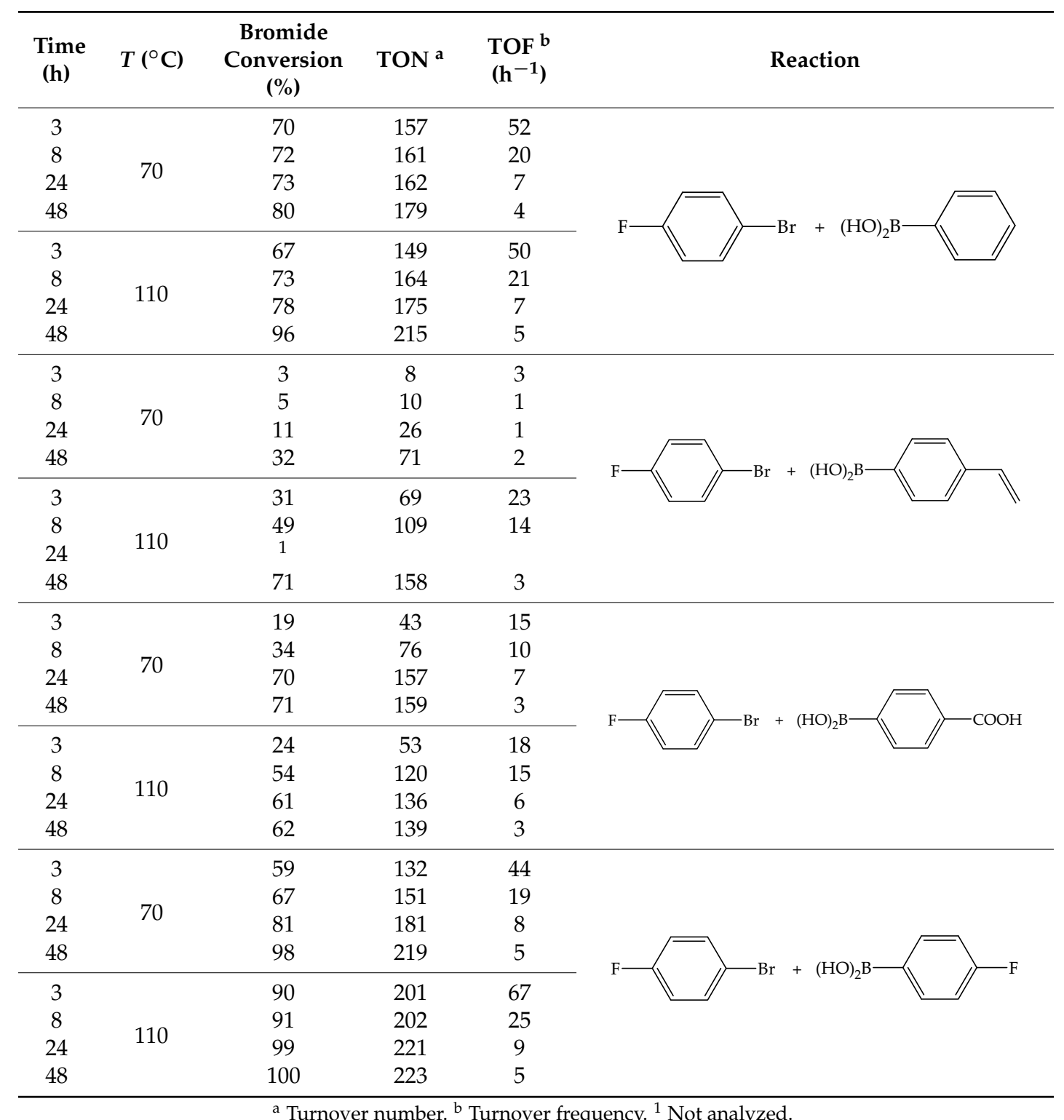

In addition, one can clearly observe that the most effective boronic acid in terms of conversion of 1-bromo-4-fluorobenzene at both studied temperatures is 4-fluorophenylboronic acid, which leads to almost complete halide conversion. The second most active boronic acid at both temperatures is phenylboronic acid which, at $3 \mathrm{~h}$ and $8 \mathrm{~h}$ reaction time at $70{ }^{\circ} \mathrm{C}$, is even slightly more active than 4-fluorophenylboronic acid. Both reactions reach almost the maximum level of halide conversion after just $3-8 \mathrm{~h}$ of reaction and the conversion does not increase significantly from 8 to $48 \mathrm{~h}$. Thus, the highest TOF value $\left(67.1 \mathrm{~h}^{-1}\right)$ found in these studies was observed for the reaction using 4-fluorophenylboronic acid at $110^{\circ} \mathrm{C}$ after $3 \mathrm{~h}$ of reaction. In the case of phenylboronic acid, the TOF values at 70 or $110^{\circ} \mathrm{C}$ were of ca. $50 \mathrm{~h}^{-1}$. In all cases, these TOF values were much higher than in the case of similar systems 
based on alumina and Pd nanoparticles [14] or mesoporous silica and palladium nanoparticles [12]. In addition, they are in the same range, if not somewhat higher, than those described for homogeneous systems based on palladium complexes used for the preparation of fluorinated biaryls [29-35].

The reactions using the other two boronic acids, 4-carboxyphenylboronic acid, and 4-vinylphenylboronic acid, showed less conversion of the halide. It appears that the reaction with 4-vinylphenylboronic acid is more temperature-sensitive than in the case of 4-carboxyphenylboronic acid as the conversions for 4-vinylphenylboronic acid at $110{ }^{\circ} \mathrm{C}$ are much higher than at $70{ }^{\circ} \mathrm{C}$. However, in the case of 4-carboxyphenylboronic acid this increase is not as high. The reaction using 4-carboxyphenylboronic acid seems to be more effective than that of 4-vinylphenylboronic acid but not comparable to phenylboronic acid or 4-fluorophenylboronic acids. The differences in the activity are presumably due to the difference in the electronic properties of the substituents. Thus, $-\mathrm{F}$ and $-\mathrm{COOH}$ have an electron-withdrawing inductive effect $-I$, while vinyl group has an electron-releasing effect $+I$. Therefore, as many mechanistic studies have proven that the only reactions involving boronic acids occur at a significant rate, is between the neutral boronic acid and oxo-palladium species [41]. It seems that the activation of the boronic group is faster in the case of $\mathrm{F}$ - and $\mathrm{COOH}$ - substituted phenylboronic acids, and this results in a higher activity.

\subsubsection{Influence of the Fluorinated Aryl Bromide}

In view of the interesting catalytic properties when using 4-fluorophenylboronic acid (which was superior to that of phenylboronic acid and 4-carboxyphenylboronic acid), this reagent was selected and used with other fluorinated bromoaryls, namely, 1-bromo-2-fluorobenzene, 1-bromo-3-fluorobenzene, 2-bromo-5-fluorotoluene, and 2-bromo-4-fluorotoluene (Scheme 2a-d, respectively), for the formation of different difluorinated biphenyls.

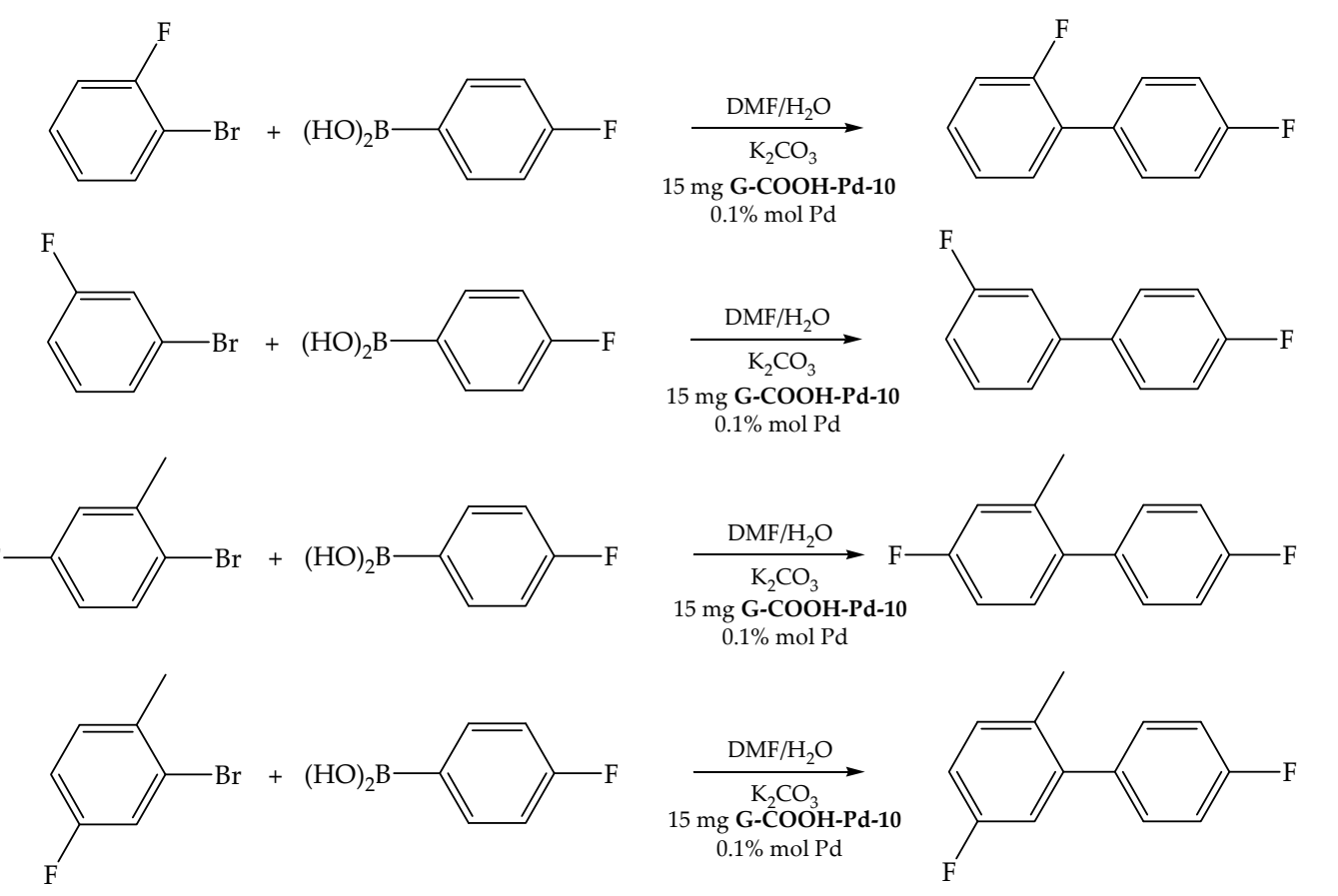

Scheme 2. Reaction of 4-fluorophenylboronic acid with (a) 1-bromo-2-fluorobenzene; (b) 1-bromo-3fluorobenzene; (c) 2-bromo-5-fluorotoluene catalyzed; and (d) 2-bromo-4-fluorotoluene by G-COOH-Pd-10. 
The results obtained in the $\mathrm{C}-\mathrm{C}$ cross-coupling reactions of Scheme 2 at different time intervals are given in Table 3 and represented in Figure 4. As occurred in the previous study, concerning the influence of boronic acids, the increase of the temperature from $70^{\circ} \mathrm{C}$ to $110^{\circ} \mathrm{C}$ again results in higher conversion percentages of the bromides. In addition, the results show that, except for 1-bromo-4-fluorotoluene and 2-bromo-4-fluorotoluene at $110{ }^{\circ} \mathrm{C}$, the reactions achieve almost the maximum conversion between 3 and $8 \mathrm{~h}$. In the case of 1-bromo-2-fluorobenzene, 1-bromo-3-fluorobenzene, and 1-bromo-4-fluorobenzene at both $70^{\circ} \mathrm{C}$ or $110^{\circ} \mathrm{C}$ and $3 \mathrm{~h}$ of reaction, the obtained TOF values were between ca. 44 and $67 \mathrm{~h}^{-1}$. In contrast, in the case of 2-bromo-5-fluorotoluene and 2-bromo-4-fluorotoluene at $70^{\circ} \mathrm{C}$ or $110^{\circ} \mathrm{C}$ and $3 \mathrm{~h}$ of reaction, the TOF values were lower, indicating an inferior activity when using this substituted bromide.

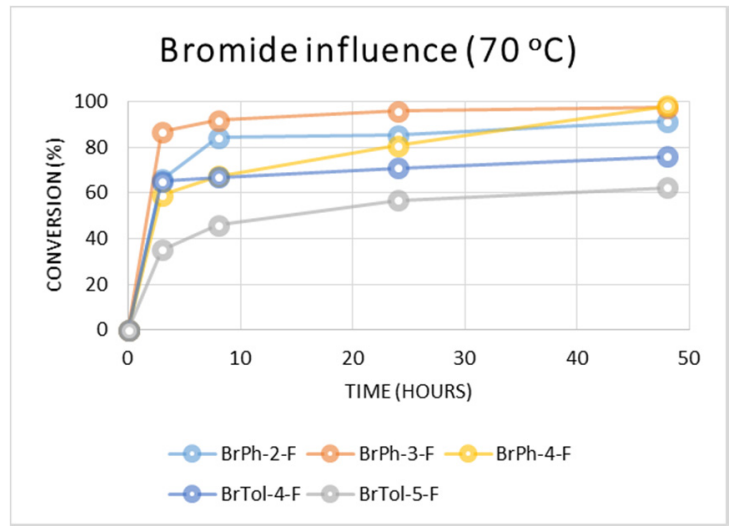

(a)

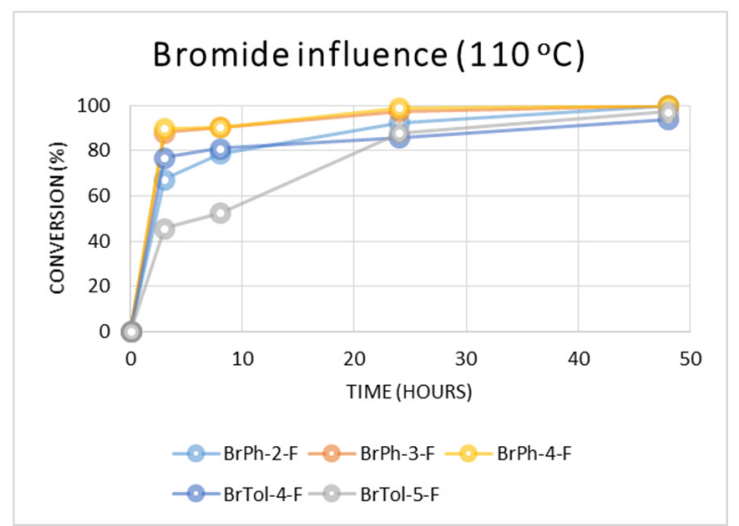

(b)

Figure 4. Conversion vs. time in the reaction of different fluorinated arylbromides and 4-fluorophenylboronic acid catalyzed by G-COOH-Pd-10: (a) at $70{ }^{\circ} \mathrm{C}$; and (b) at $110{ }^{\circ} \mathrm{C}$.

It seems clear that the position of the fluorine substituent at the phenyl ring does not have a remarkable influence in the catalytic activity. Thus, the steric effect does not seem to be determinant for their reactivity. However, in the case of 1-bromo-4-fluorotoluene and 2-bromo-4-fluorotoluene, the incorporation of the methyl group in ortho-position to the bromine atom, results in a decrease of the catalytic activity due to both the steric hindrance and the electronic $+I$ effect of the methyl group in the bromide, which decrease the catalytic activity.

Finally, we have carried out the reaction between 4-fluorobenzeneboronic acid and 1-chloro-4-fluorobenzene observing halide conversion after $48 \mathrm{~h}$ of ca. $12 \%$. However, from the reaction mixture we were unable to isolate the coupling product observing various unidentified F-containing compounds. This indicates the limited applicability in coupling reactions of these systems when starting from arylchlorides.

\subsubsection{Recyclability Tests}

It is well known that one of the most important advantages of heterogeneous catalytic systems is the possibility of recovery and recyclability. Thus, a series of catalytic tests were carried out to determine the degree of loss of activity of the synthesized catalyst G-COOH-Pd-10 after several consecutive catalytic cycles. The studied recyclability tests were performed using similar experimental conditions, but tested in up to five consecutive catalytic cycles. The selected reagents for this study of recyclability were 1-bromo-4-fluorobenzene and 4-fluorophenylboronic acid (highest TOF values). After each catalytic cycle, the catalyst was centrifuged and washed with water and diethylether, dried under vacuum, and then used in the subsequent catalytic test. 
Table 3. Halide conversions in C-C coupling reactions using 4-fluorophenylboronic acid and different fluorinated arylbromides catalyzed by G-COOH-Pd-10.

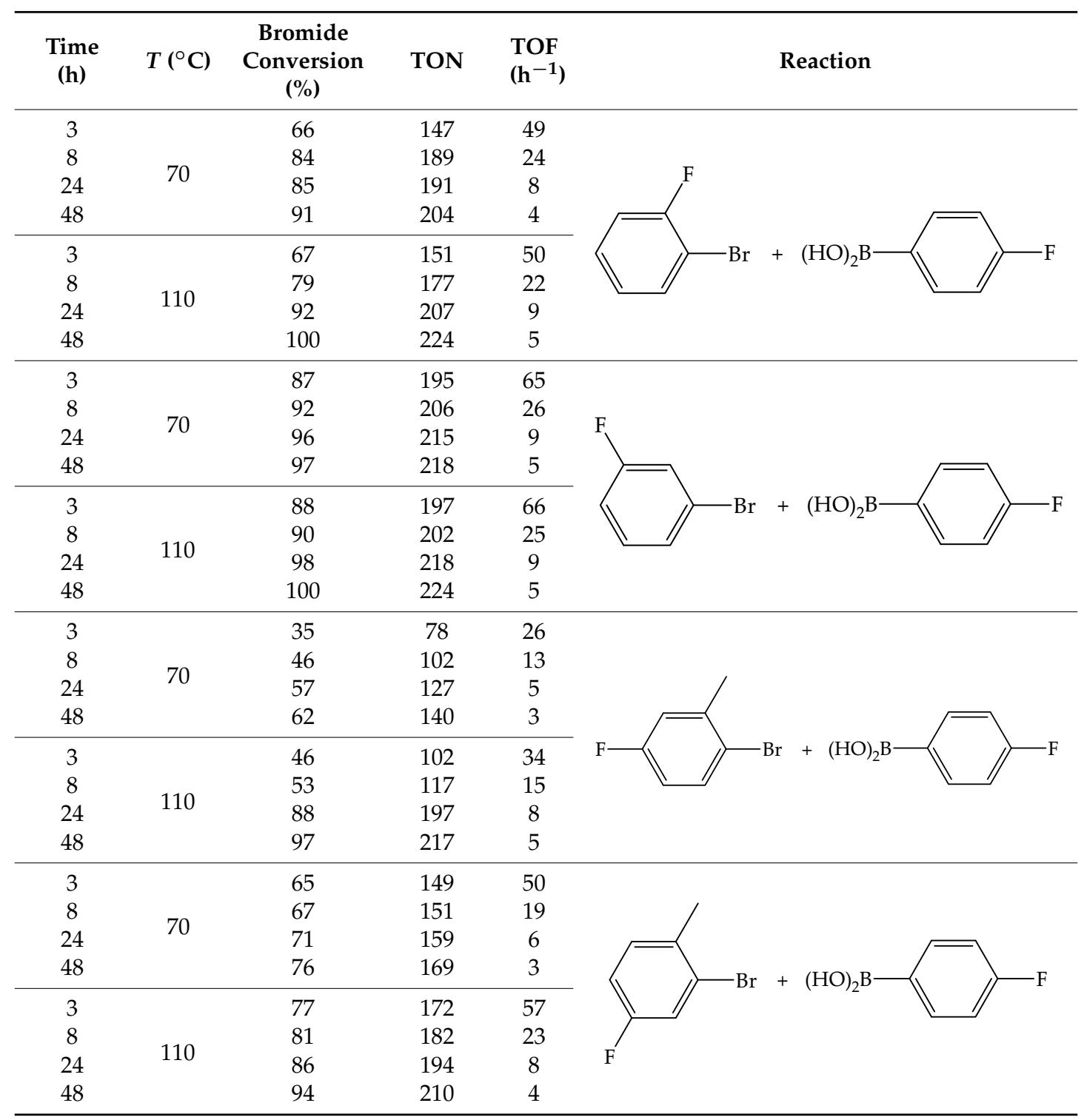

For the studied reaction, a very low loss of activity (less than 10\%) of the catalyst G-COOH-Pd-10 was observed after the five catalytic cycles (Figure 5). It is important to note that these systems based on palladium nanoparticles may lead to agglomeration of the nanoparticles after the first or subsequent cycles because of the mobility of the palladium nanoparticles at high temperatures. This effect has previously been observed in similar hybrid systems based on mesoporous silica [12] and graphene oxide [16], but not significantly in alumina-based materials [14], or graphene oxide when using microwaves [16]. In the case of G-COOH-Pd-10 the very small loss of activity suggests that there is no formation of big clusters of Pd nanoparticles as this would lead to deactivation of the catalyst. 


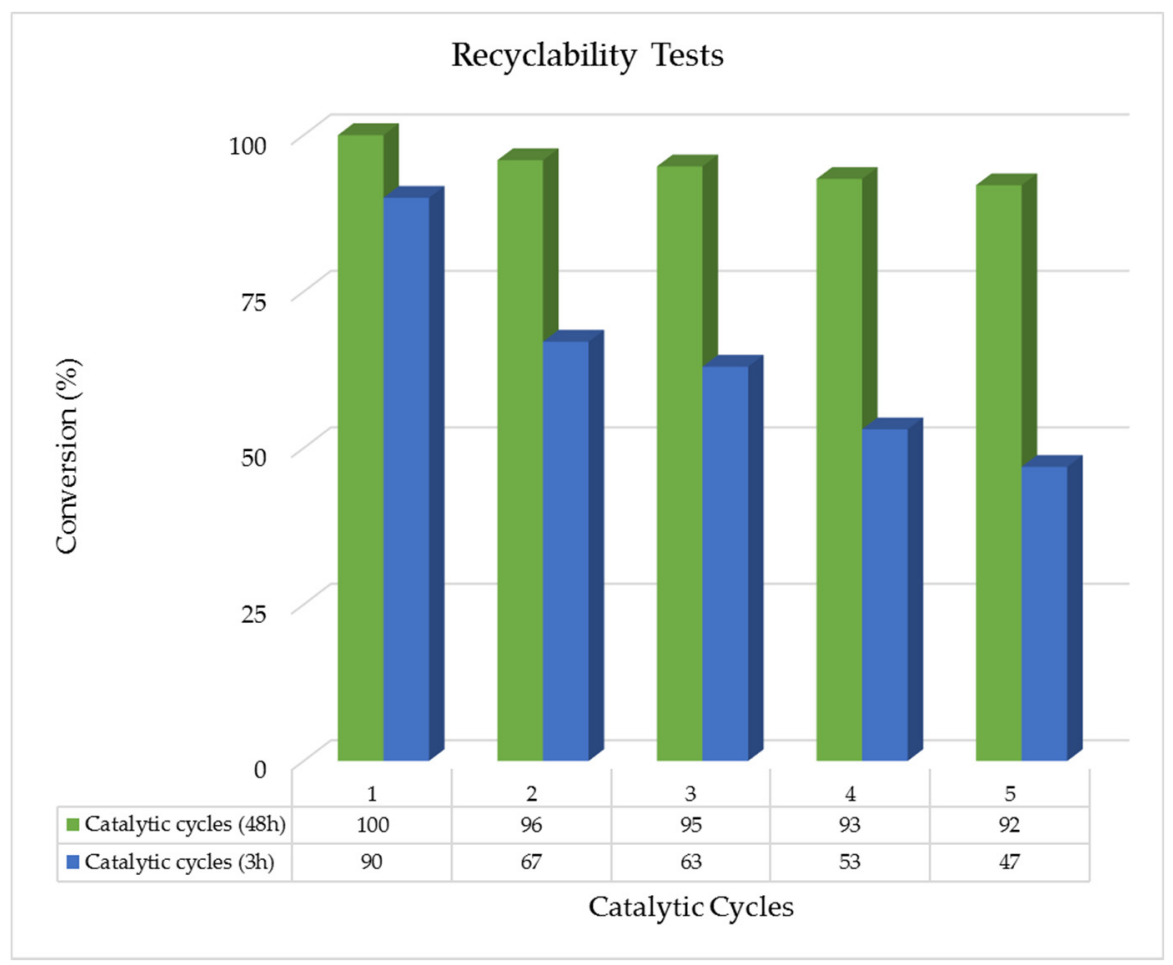

Figure 5. Recyclability tests of the consecutive reactions of 1-bromo-4-fluorobenzene and 4-fluorophenylboronic acid at $110{ }^{\circ} \mathrm{C}$ for $48 \mathrm{~h}$ (green) or $3 \mathrm{~h}$ (blue) catalyzed by G-COOH-Pd-10.

We have carried out additional recyclability tests using a reaction time of $3 \mathrm{~h}$. We have observed a progressive loss of activity in the consecutive tests at $3 \mathrm{~h}$ from $90 \%$ to $47 \%$ after the fifth cycle (Figure 5). This did not happen at $48 \mathrm{~h}$ probably because the reaction time is higher and, therefore, compensates for the loss of activity.

Thus, in order to determine the reason of the loss of activity, we measured the Pd leaching in the solution by XRF although we were unable to determine Pd in concentrated solutions. However, when we carried out a TEM measurement of the material after the fifth catalytic cycle (Figure 6), we observed the formation of clusters of palladium nanoparticles which agglomerate and, therefore, cause a decrease in the catalytic activity.

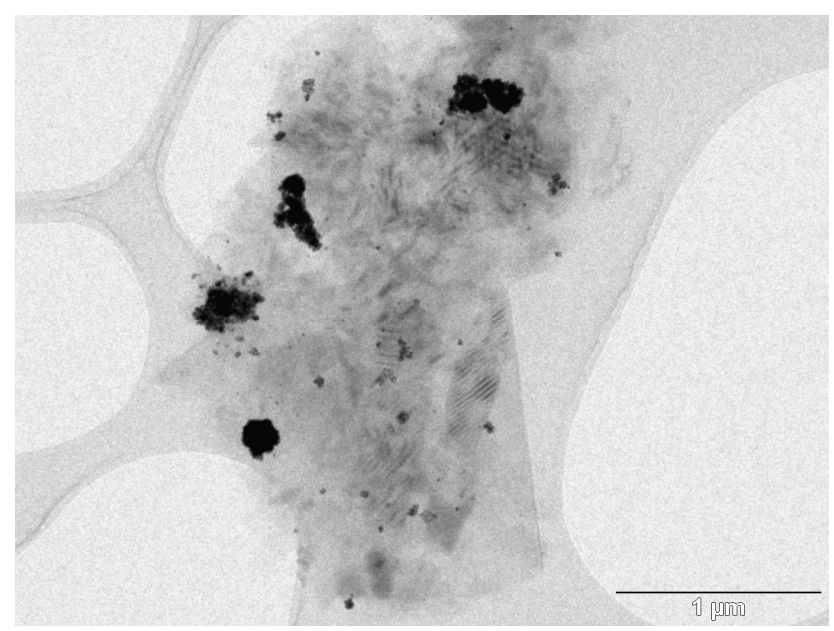

Figure 6. Transmission electronic microscopy (TEM) image of G-COOH-Pd-10 after five consecutive catalytic cycles. 


\section{Materials and Methods}

\subsection{General Conditions}

All manipulations were performed under dry nitrogen gas using standard Schlenk techniques and a dry box. Solvents were distilled from the appropriate drying agents and degassed before use. Graphene modified with $\mathrm{COOH}$ groups UGRAYTM_COOH (Graphene-carboxyl, G-COOH) was purchased from United Nanotech (Karnataka, India) and was used as purchased, after a simple dehydration process (see Section 3.3.2.). Water (resistance $18.2 \mathrm{M} \Omega \cdot \mathrm{cm}$ ) used in the study was obtained from a Millipore Milli-Q-System (Billerica, MA, USA).

\subsection{General Remarks on the Characterization of the Materials}

X-ray diffraction (XRD) patterns of the hybrid materials were obtained on a Philips Diffractometer model PW3040/00 X'Pert MPD/MRD at $45 \mathrm{KV}$ and $40 \mathrm{~mA}$, using a wavelength $\mathrm{Cu} \mathrm{K} \alpha$ $(\lambda=1.5418 \AA)$. Pd wt \% determination by X-ray fluorescence was carried out with a $\mathrm{X}$-ray fluorescence spectrophotometer Philips MagiX with an X-ray source of $1 \mathrm{~kW}$ and a Rh anode using a helium atmosphere. The quantification method is capable of analyzing from $0.0001 \%$ to $100 \% \mathrm{Pd}$. $\mathrm{N}_{2}$ gas adsorption-desorption isotherms were performed using a Micromeritics ASAP 2020 analyzer (Micromeritics, Norcross, GA., USA). Conventional transmission electron microscopy (TEM) was carried out on a TECNAI 20 Philips unit (Philips, Eindhoven, The Netherlands), operating at $200 \mathrm{kV}$.

\subsection{Preparation of the Hybrid Materials G-COOH-Pd-X}

\subsubsection{Preparation of the Palladium Precursor}

$\mathrm{PdCl}_{2}(1.53 \mathrm{~g}, 8.6 \mathrm{mmol})$ was dissolved in $6 \mathrm{~mL}$ of concentrated $\mathrm{HCl}$. The cooled solution was diluted with $150 \mathrm{~mL}$ of absolute ethanol and passed through a filter paper; the residue and filter paper were then washed with $2 \times 10 \mathrm{~mL}$ of ethanol. Afterwards, 1,5-cyclooctadiene (2.5 mL, 20.4 mmol) was added to the resulting solution under stirring. The color of the solution turned from brown to orange and the solid product precipitated immediately. The reaction was stirred for an additional 20 min and then filtered and the yellow-orange solid washed with diethylether $(3 \times 10 \mathrm{~mL})$. The final product was dried under vacuum overnight giving $2.32 \mathrm{~g}$ (16.4 mmol) of [ $\left.\mathrm{PdCl}_{2}(\mathrm{cod})\right]$ (yield: 97\%).

\subsubsection{Dehydration of G-COOH}

In order to reduce the quantity of physisorbed solvents or water on the external surface area of $\mathrm{G}-\mathrm{COOH}$, activation by dehydration of the corresponding material was carried out at $150{ }^{\circ} \mathrm{C}$ under vacuum.

\subsubsection{Pd-Loading Study}

Functionalization of G-COOH has been studied using different quantities of Pd precursor $\left[\mathrm{PdCl}_{2}(\mathrm{cod})\right]$ and one gram of G-COOH. Table $\mathrm{S} 1$ of the supplementary material shows the quantity of palladium complex and G-COOH employed in each reaction.

The general procedure for the preparation of the Pd-supported nanoparticles was carried out using a similar method to that published by our group for titanium oxide-based materials $[12,14,37,38]$ : In summary, the corresponding amount of $\mathrm{G}-\mathrm{COOH}(1.0 \mathrm{~g})$ and $\left[\mathrm{PdCl}_{2}(\mathrm{cod})\right](141.2 \mathrm{mg}$, for a theoretical Pd loading of $5 \mathrm{wt} \%$ ) were added to a Schlenk tube and dried under vacuum for $1 \mathrm{~h}$ at room temperature. Subsequently, $50 \mathrm{~mL}$ of toluene (THF) was added under an inert atmosphere. The reaction mixture was then heated to $110{ }^{\circ} \mathrm{C}$ and stirred for $48 \mathrm{~h}$. The resulting material was isolated by filteration and washed with toluene, water and diethylether $(2 \times 50 \mathrm{~mL}$ each $)$. The material was dried under vacuum for $12 \mathrm{~h}$ to remove all trace of solvents. 


\subsection{Catalytic Study}

\subsubsection{Determination of the Optimal Conditions and Influence of the Boronic Acid}

The study was focused on the reaction of 1-bromo-4-fluorobenzene with different boronic acids, two different temperatures were tested $\left(70\right.$ and $\left.110^{\circ} \mathrm{C}\right)$ and the reactions were monitored after 3,8 , 24 , and $48 \mathrm{~h}$ reaction time. The different boronic acids used in the reaction were phenylboronic acid, 4-vinylphenylboronic acid, 4-carboxyphenylboronic acid and 4-fluorophenylboronic acid (Scheme 1a-d, respectively). The reactions were performed under identical conditions in order to facilitate a subsequent analysis of the results. In all the reactions, the limiting reagent was 1-bromo-4-fluorobenzene, the molar ratio between the halide and the boronic acid was 1:1.2, the molar ratio between the halide and the base $\left(\mathrm{K}_{2} \mathrm{CO}_{3}\right)$ was $1: 2$ and the amount of catalyst was in all cases $15 \mathrm{mg}$. All the reactions were carried out using degassed solvents and under a nitrogen atmosphere to achieve higher final conversions [42].

Reaction of 1-bromo-4-fluorobenzene with phenylboronic acid derivatives: a stock solution of 1-bromo-4-fluorobenzene $(262 \mathrm{mg}, 1.5 \mathrm{mmol})$ in a mixture of degassed solvents (DMF: $\mathrm{H}_{2} \mathrm{O}$ 95:5, $15 \mathrm{~mL}$ ) was carried out under nitrogen in a Schlenk tube. Subsequently, Schlenk flasks were filled with either phenylboronic acid $(36.6 \mathrm{mg}, 0.300 \mathrm{mmol})$, 4-vinylphenylboronic acid $(44.4 \mathrm{mg}$, $0.300 \mathrm{mmol}$ ), 4-carboxyphenylboronic acid $(49.8 \mathrm{mg}, 0.300 \mathrm{mmol})$, or 4-fluorophenylboronic acid (42.0 mg, $0.300 \mathrm{mmol}), \mathrm{K}_{2} \mathrm{CO}_{3}(69.1 \mathrm{mg}, 0.5 \mathrm{mmol})$, and Pd catalyst (15 mg G-COOH-Pd-10, $1.18 \mathrm{mg}$ of $\mathrm{Pd}, 1.11 \cdot 10^{-3} \mathrm{mmol} \mathrm{Pd}, 0.44 \%$ molar ratio bromide: $\mathrm{Pd}, 0.1 \% \mathrm{~mol} \mathrm{Pd}$ in the reaction). Three vacuum $/ \mathrm{N}_{2}$ cycles (10 $\mathrm{min} / 1 \mathrm{~min}$ ) were carried out to remove oxygen from the reaction atmosphere and adsorbed water from the solids. Afterwards, $2.5 \mathrm{~mL}$ ( $0.25 \mathrm{mmol})$ of the stock solution of 1-bromo-4-fluorobenzene were transferred under $\mathrm{N}_{2}$ to the Schlenk flasks containing the solid mixtures. The suspension was then heated to the corresponding temperature $\left(70^{\circ} \mathrm{C}\right.$ or $\left.110^{\circ} \mathrm{C}\right)$ using a condenser and stirred for 3,8 , 24 , or $48 \mathrm{~h}$. After this time, the solution was cooled to room temperature and filtered over a nylon filter $(0.4 \mu \mathrm{m})$.

\subsubsection{Quantification of the Conversion of 1-Bromo-4-Fluorobenzene}

For the quantification of the conversion of 1-bromo-4-fluorobenzene, $0.3 \mathrm{~mL}$ of each resulting solution of the reactions was mixed together with $0.3 \mathrm{~mL}$ of a standard $2.5 \mathrm{wt} \%$ solution of 4-fluorobenzophenone in deuterated acetone. An additional NMR tube (blank) was prepared by mixing $0.3 \mathrm{~mL}$ of the original solution of 1-bromo-4-fluorobenzene $(262 \mathrm{mg}, 1.5 \mathrm{mmol})$ in a mixture of degassed solvents (DMF: $\mathrm{H}_{2} \mathrm{O}$ 95:5, $15 \mathrm{~mL}$ ) with $0.3 \mathrm{~mL}$ of a standard $1.0 \% v / v$ solution of 4 -fluorobenzophenone in deuterated acetone. The quantification was carried out by comparison of the ratio of the integral of the signal of the fluorine atom in 1-bromo-4-fluorobenzene $(\delta-111.7 \mathrm{ppm})$ with that of the standard (4-fluorobenzophenone, $\delta-102.9 \mathrm{ppm}$ ) before and after the reaction. The chosen internal standard was 4-fluorobenzophenone (final concentration of $0.75 \% v / v$ ), an inert compound with respect to reagents and products and that has a very different chemical shift to that of the other compounds. The solution samples were always in the range of the concentration of 1-bromo-4-fluorobenzene of the calibration curve. The calibration curve was prepared using a concentration of 1-bromo-4-fluorobenzene in the range 0.005-0.1 M. Using this method, the molar quantification of the conversion of 1-bromo-4-fluorobenzene was carried out. For an example of the ${ }^{19} \mathrm{~F}$ NMR spectra of the reaction between 1-bromo-4-fluorobenzene and phenylboronic acid see Figures S7-S12 of the Supplementary Material.

\subsubsection{Isolation of the Coupling Products}

For the isolation of the product, the solvent of the filtrated solution after $48 \mathrm{~h}$ of reaction was eliminated under vacuum and the solid or oily residue was dissolved in $\mathrm{CDCl}_{3}$ and analyzed by ${ }^{1} \mathrm{H}$, and ${ }^{19} \mathrm{~F}$ NMR spectroscopy. For further details of all the synthesized fluorinated biaryl derivatives see section Spectroscopic Data $\left({ }^{1} \mathrm{H}\right.$ and ${ }^{19} \mathrm{~F}$ NMR) of the Supplementary Material. 


\subsubsection{Reactions of Different Fluorinated Aryl Bromides with 4-Fluorophenylboronic Acid}

In order to determine the influence of different fluorinated aryl bromides in the catalytic C-C coupling reaction, additional reactions of 1-bromo-3-fluorobenzene, 1-bromo-2-fluorobenzene, 2-bromo-5-fluorotoluene, or 2-bromo-4-fluorotoluene with 4-fluorophenylboronic acid were carried out (Scheme 2a-d), following a similar procedure to that described in the Section 3.4.2 using temperatures of $70{ }^{\circ} \mathrm{C}$ and $110{ }^{\circ} \mathrm{C}$ and reaction times of $3,8,24$, or $48 \mathrm{~h}$. In this case, the quantification was carried out by comparison of the ratio of the integral of the signal of the fluorine atom in the ${ }^{19} \mathrm{~F} N \mathrm{NR}$ spectrum of 1-bromo-3-fluorobenzene ( $\delta-106.9 \mathrm{ppm}), 1$-bromo-2-fluorobenzene $(\delta-104.4 \mathrm{ppm})$, 2-bromo-5-fluorotoluene $(\delta-112.0 \mathrm{ppm})$, or 2-bromo-4-fluorotoluene $(\delta-112.0 \mathrm{ppm})$ with that of the standard (4-fluorobenzophenone, $\delta 102.9 \mathrm{ppm}$ ) before and after the reaction. For an example of the ${ }^{19} \mathrm{~F}$ NMR spectra of the reaction between 4-fluorophenylboronic acid and 1-bromo-2-fluorobenzene see Figure S13 of the Supplementary Material.

\subsubsection{Studies of the Catalyst Recyclability}

Additional catalytic tests were carried out to determine the loss of activity of the catalyst after several catalytic cycles. Recyclability tests were carried out using similar experimental procedures but tested in up to five consecutive catalytic cycles. The reactions were performed on a larger scale, but under the same experimental conditions. The tests were conducted using a higher starting amount of catalyst $(75 \mathrm{mg})$ in order to be able to carry out up to five catalytic cycles. After each cycle, the catalyst was centrifuged and washed with water $(2 \times 100 \mathrm{~mL})$ and diethylether $(2 \times 30 \mathrm{~mL})$.

\section{Conclusions}

In this work we have synthesized a hybrid heterogeneous catalyst based on Pd-supported nanoparticles onto $\mathrm{COOH}$-modified graphite support in a mixture of phases (G-COOH-Pd-10). This material has shown interesting catalytic behavior in the Suzuki-Miyaura coupling reaction of fluorinated aryls with TOF values of up to $67 \mathrm{~h}^{-1}$ which are higher than those found for reported homogeneous palladium complexes in similar reactions for the formation of fluorinated biaryls. In addition, the recyclability of the system G-COOH-Pd-10 at short $3 \mathrm{~h}$ reaction time shows a progressive loss of activity in the catalytic tests from $90 \%$ to $47 \%$ after the fifth cycle. However, this material showed a good degree of recyclability with a low deactivation of less than $8 \%$ after up to five catalytic cycles after 48 hours, probably due to the longer reaction time compensating for the loss of activity.

Supplementary Materials: The following are available online at www.mdpi.com/2073-4344/7/3/76/s1. Table S1: Experimental quantities of reagents for the Pd loading study; Table S2: Adsorptive parameters of the materials G-COOH and G-COOH-Pd-10; Figure S1: TEM image of G-COOH showing the single layer of graphene; Figure S2: TEM image of a cluster of agglomerated Pd nanoparticles; Figure S3: TEM image showing the impregnation of a cluster of Pd nanoparticles at the edge of the graphene layer; Figure S4: FT-IR spectrum of G-COOH-Pd-10; Figure S5: Nitrogen adsorption desorption isotherm of G-COOH; Figure S6: XRD of the material G-COOH-Pd-10; Figure S7: Comparison of the ${ }^{19} \mathrm{~F}$ NMR spectra of the reaction between 1-bromo-4-fluorobenzene and phenylboronic acid catalyzed by G-COOH-Pd-10 in the presence of a constant quantity of standard (4-fluorobenzophenone) at different reaction time periods; Figure S8: ${ }^{19}$ F NMR spectrum of the starting solution of 1-bromo-4-fluorobenzene in the presence of a constant quantity of standard (4-fluorobenzophenone) (0 hours); Figures S9-S12: ${ }^{19}$ F NMR spectrum of the reaction between 1-bromo-4-fluorobenzene and phenylboronic acid catalyzed by G-COOH-Pd-10 after 3, 8, 24, and 48 hours of reaction in the presence of a constant quantity of standard (4-fluorobenzophenone), Figure S13: Comparison of the ${ }^{19} \mathrm{~F}$ NMR spectra of the reaction between 1-bromo-2-fluorobenzene and 4-fluorophenylboronic acid catalyzed by G-COOH-Pd-10 in the presence of a constant quantity of standard (4-fluorobenzophenone) at different reaction time periods. In addition, the spectroscopic data $\left({ }^{1} \mathrm{H}\right.$ and $\left.{ }^{19} \mathrm{~F} \mathrm{NMR}\right)$ of all the fluorinated biaryl derivatives are included.

Acknowledgments: We gratefully acknowledge financial support from the Ministerio de Economía y Competitividad, Spain (Grant no. CTQ2015-66164-R). We would also like to thank Universidad Rey Juan Carlos and Banco de Santander for supporting our Research Group of Excellence QUINANOAP. We would also like to thank Isfahan University of Technology for the partial financial support of the research stay of R.S.E. Finally, we thank Sandra Carralero and Carmen Forcé for their valuable advice with NMR experiments. 
Author Contributions: S.G-R. conceived and designed the experiments; R.S.E. and D.D.-G. performed the experiments; S.G-R., R.S.E., D.D.-G., S.P., M.A., A.R.-D., and M.F. analyzed the data and contributed with different analysis tools; finally, S.G-R., R.S.E., D.D.-G., and S.P. wrote the paper.

Conflicts of Interest: The authors declare no conflict of interest. The funding sponsors had no role in the design of the study; in the collection, analyses, or interpretation of data; in the writing of the manuscript, and in the decision to publish the results.

\section{References}

1. Seechurn, C.C.C.J.; Kitching, M.O.; Colacot, T.J.; Snieckus, V. Palladium-Catalyzed Cross-Coupling: A Historical Contextual Perspective to the 2010 Nobel Prize. Angew. Chem. Int. Ed. 2012, 51, 5062-5085. [CrossRef] [PubMed]

2. Maluenda, I.; Navarro, H. Recent Developments in the Suzuki-Miyaura Reaction: 2010-2014. Molecules 2015, 20, 7528-7557. [CrossRef] [PubMed]

3. Miyaura, N.; Suzuki, A. Palladium-Catalyzed Cross-Coupling Reactions of Organoboron Compounds. Chem. Rev. 1995, 95, 2457-2483. [CrossRef]

4. Nicolaou, K.C.; Bulger, P.G.; Sarlah, D. Palladium-Catalyzed Cross-Coupling Reaction in Total Synthesis. Angew. Chem. Int. Ed. 2005, 44, 4442-4489. [CrossRef] [PubMed]

5. Kotha, S.; Lahiri, K.; Kashinath, D. Recent Applications of the Suzuki-Miyaura Cross-Coupling Reaction in Organic Synthesis. Tetrahedron 2002, 58, 9633-9695. [CrossRef]

6. Schlögl, R. Heterogeneous Catalysis. Angew. Chem. Int. Ed. 2015, 54, 3465-3520. [CrossRef] [PubMed]

7. Polshettiwar, V.; Len, C.; Fihri, A. Silica-supported palladium: Sustainable catalysts for cross-coupling reactions. Coord. Chem. Rev. 2009, 253, 2599-2626. [CrossRef]

8. Kann, N. Recent Applications of Polymer Supported Organometallic Catalysts in Organic Synthesis. Molecules 2010, 15, 6306-6331. [CrossRef] [PubMed]

9. Bej, A.; Ghosh, K.; Sarkar, A.; Knight, D.W. Palladium nanoparticles in the catalysis of coupling reactions. RSC Adv. 2016, 6, 11446-11453. [CrossRef]

10. Pérez-Lorenzo, M. Palladium Nanoparticles as Efficient Catalysts for Suzuki Cross-Coupling Reactions. J. Phys. Chem. Lett. 2012, 3, 167-174. [CrossRef]

11. Parlett, C.M. A.; Bruce, D.W.; Hondow, N.S.; Newton, M.A.; Lee, A.F.; Wilson, K. Mesoporous Silicas as Versatile Supports to Tune the Palladium-Catalyzed Selective Aerobic Oxidation of Allylic Alcohols. ChemCatChem 2013, 5, 939-950. [CrossRef]

12. Balbín, A.; Gaballo, F.; Ceballos-Torres, J.; Prashar, S.; Fajardo, M.; Kaluderovic, G.N.; Gómez-Ruiz, S. Dual application of Pd nanoparticles supported on mesoporous silica SBA-15 and MSU-2: Supported catalysts for $\mathrm{C}-\mathrm{C}$ coupling reactions and cytotoxic agents against human cancer cell lines. RSC Adv. 2014, 4, 54775-54787. [CrossRef]

13. Kumar, A.P.; Kumar, B.P.; Kumar, A.B.V.K.; Huy, B.T.; Lee, Y.-I. Preparation of palladium nanoparticles on alumina surface by chemical co-precipitation method and catalytic applications. Appl. Surface Sci. 2013, 265, 500-509. [CrossRef]

14. Hossain, A.M.S.; Balbín, A.; Erami, R.S.; Prashar, S.; Fajardo, M.; Gómez-Ruiz, S. Synthesis and study of the catalytic applications in $\mathrm{C}-\mathrm{C}$ coupling reactions of hybrid nanosystems based on alumina and palladium nanoparticles. Inorg. Chim. Acta 2017, 455, 645-652. [CrossRef]

15. Siamaki, A.R.; Khder, A.E.R.S.; Abdelsayed, V.; El-Shall, M.S.; Gupton, B.F. Microwave-assisted synthesis of palladium nanoparticles supported on graphene: A highly active and recyclable catalyst for carbon-carbon cross-coupling reactions. J. Catal. 2011, 279, 1-11. [CrossRef]

16. Gómez-Martínez, M.; Buxaderas, E.; Pastor, I.M.; Alonso, D.A. Palladium nanoparticles supported on graphene and reduced graphene oxide as efficient recyclable catalyst for the Suzuki-Miyaura reaction of potassium aryltrifluoroborates. J. Mol. Catal. A: Chem. 2015, 404-405, 1-7. [CrossRef]

17. Joshi, H.; Sharma, K.N.; Sharma, A.K.; Singh, A.K. Palladium-phosphorus/sulfur nanoparticles (NPs) decorated on graphene oxide: Synthesis using the same precursor for NPs and catalytic applications in Suzuki-Miyaura coupling. Nanoscale 2014, 6, 4588-4597. [CrossRef] [PubMed]

18. Movahed, S.K.; Esmatpoursalmani, R.; Bazgir, A. N-Heterocyclic carbene palladium complex supported on ionic liquid-modified graphene oxide as an efficient and recyclable catalyst for Suzuki reaction. RSC Adv. 2014, 4, 14586-14591. [CrossRef] 
19. Yamamoto, S.-I.; Kinoshita, H.; Hashimoto, H.; Nishina, Y. Facile preparation of Pd nanoparticles supported on single-layer graphene oxide and application for the Suzuki-Miyaura cross-coupling reaction. Nanoscale 2014, 6, 6501-6505. [CrossRef] [PubMed]

20. Rumi, L.; Scheuermann, G.M.; Mülhaupt, R.; Bannwarth, W. Palladium Nanoparticles on Graphite Oxide as Catalyst for Suzuki-Miyaura, Mizoroki-Heck, and Sonogashira Reactions. Helv. Chim. Acta 2011, 94, 966-976. [CrossRef]

21. Lin, J.; Mei, T.; Lv, M.; Zhang, C.; Zhao, Z.; Wang, X. Size-controlled PdO/graphene oxides and their reduction products with high catalytic activity. RSC Adv. 2014, 4, 29563-29570. [CrossRef]

22. Hattori, T.; Tsubone, A.; Sawama, Y.; Monguchi, Y.; Sajiki, H. Palladium on Carbon-Catalyzed Suzuki-Miyaura Coupling Reaction Using an Efficient and Continuous Flow System. Catalysts 2015, 5, 18-25. [CrossRef]

23. Groult, H.; Leroux, F.; Tressaud, A. Modern synthesis Processes and Reactivity of Fluorinated Compounds; Elsevier: London, UK, 2017.

24. Wang, J.; Sánchez-Roselló, M.; Aceña, J.L.; del Pozo, C.; Sorochinsky, A.E.; Fustero, S.; Soloshonok, V.A.; Liu, H. Fluorine in Pharmaceutical Industry: Fluorine-Containing Drugs Introduced to the Market in the Last Decade (2001-2011). Chem. Rev. 2014, 114, 2432-2506. [CrossRef] [PubMed]

25. Murphy, C.D. Drug metabolism in microorganisms. Biotechnol. Lett. 2015, 37, 19-28. [CrossRef] [PubMed]

26. Berger, R.; Resnati, G.; Metrangolo, P.; Weberd, E.; Hulliger, J. Organic fluorine compounds: A great opportunity for enhanced materials properties. Chem. Soc. Rev. 2011, 40, 3496-3508. [CrossRef] [PubMed]

27. Coates, D.; Greenfield, S.; Smith, G.; Chambers, M.K.; Kurmeier, H.-A.; Dorsch, D. Fluorinated biphenyl derivatives. Merck, Darmstadt, Germany. WO1990015115, 1990.

28. Hampton, A.S.; Mikulski, L.; Palmer-Brown, W.; Murphy, C.D.; Sandford, G. Evaluation of fluorinated biphenyl ether pro-drug scaffolds employing the chemical-microbial approach. Bioorg. Med. Chem. Lett. 2016, 26, 2255-2258. [CrossRef] [PubMed]

29. Fang, X.; Huang, Y.; Chen, X.; Lin, X.; Bai, Z.; Huang, K.-W.; Yuan, Y.; Weng, Z. Preparation of fluorinated biaryls through direct palladium-catalyzed coupling of polyfluoroarenes with aryltrifluoroborates. J. Fluorine Chem. 2013, 151, 50-57. [CrossRef]

30. Wei, Y.; Su, W. Pd(OAc) $)_{2}$-Catalyzed Oxidative C-H/C-H Cross-Coupling of Electron-Deficient Polyfluoroarenes with Simple Arenes. J. Am. Chem. Soc. 2010, 132, 16377-16379. [CrossRef] [PubMed]

31. Li, H.; Liu, J.; Sun, C.-L.; Li, B.-J.; Shi, Z.-J. Palladium-Catalyzed Cross-Coupling of Polyfluoroarenes with Simple Arenes. Org. Lett. 2011, 13, 276-279. [CrossRef] [PubMed]

32. Liu, N.; Liu, C.; Jin, Z. Green synthesis of fluorinated biaryl derivatives via thermoregulated ligand/palladium-catalyzed Suzuki reaction. J. Organomet. Chem. 2011, 696, 2641-2647. [CrossRef]

33. Liu, Y.; Wang, J. Synthesis of 4-Substituted Styrene Compounds via Palladium-Catalyzed Suzuki Coupling Reaction Using Free Phosphine Ligand in Air. Synth. Commun. 2010, 40, 196-205. [CrossRef]

34. Wang, Z.-Y.; Ma, Q.-M.; Lia, R.-H.; Shao, L.-X. Palladium-catalyzed Suzuki-Miyaura coupling of aryl sulfamates with arylboronic acids. Org. Biomol. Chem. 2013, 11, 7899-7906. [CrossRef] [PubMed]

35. Wang, Z.-Y.; Chen, G.-Q.; Shao, L.-X. N-Heterocyclic Carbene-Palladium(II)-1-Methylimidazole Complex-Catalyzed Suzuki-Miyaura Coupling of Aryl Sulfonates with Arylboronic Acids. J. Org. Chem. 2012, 77, 6608-6614. [CrossRef] [PubMed]

36. Kurscheid, B.; Belkoura, L.; Hoge, B. Air-Stable and Catalytically Active Phosphinous Acid Transition-Metal Complexes. Organometallics 2012, 31, 1329-1334. [CrossRef]

37. Lázaro-Navas, S.; Prashar, S.; Fajardo, M.; Gómez-Ruiz, S. Visible light-driven photocatalytic degradation of the organic pollutant methylene blue with hybrid palladium-fluorine-doped titanium oxide nanoparticles. J. Nanopart. Res. 2015, 17, 94. [CrossRef]

38. Rico-Oller, B.; Boudjemaa, A.; Bahruji, H.; Kebir, M.; Prashar, S.; Bachari, K.; Fajardo, M.; Gómez-Ruiz, S. Photodegradation of organic pollutants in water and green hydrogen production via methanol photoreforming of doped titanium oxide nanoparticles. Sci. Total Environ. 2016, 563-564, 921-932. [CrossRef] [PubMed]

39. Schneider, C.A.; Rasband, W.S.; Eliceiri, K.W. NIH Image to ImageJ: 25 years of image analysis. Nat. Methods 2012, 9, 671-675. [CrossRef] [PubMed] 
40. Sing, K.S.W.; Everett, D.H.; Haul, R.A.W.; Moscou, L.; Pierotti, R.A.; Rouquerol, J.; Siemieniewska, T. Reporting physisorption data for gas/solid systems with special reference to the determination of surface area and porosity (Recommendations 1984). Pure Appl. Chem. 1985, 57, 603-619. [CrossRef]

41. Lennox, A.J. J.; Lloyd-Jones, G.C. Selection of boron reagents for Suzuki-Miyaura coupling. Chem. Soc. Rev. 2014, 43, 412-443. [CrossRef] [PubMed]

42. Trilla, M.; Borja, G.; Pleixats, R.; Man, M.W.C.; Bied, C.; Moreau, J.J.E. Recoverable Palladium Catalysts for Suzuki-Miyaura Cross-Coupling Reactions Based on Organic-Inorganic Hybrid Silica Materials Containing Imidazolium and Dihydroimidazolium Salts. Adv. Synth. Catal. 2008, 350, 2566-2574. [CrossRef]

(C) 2017 by the authors. Licensee MDPI, Basel, Switzerland. This article is an open access article distributed under the terms and conditions of the Creative Commons Attribution (CC BY) license (http:/ / creativecommons.org/licenses/by/4.0/). 